
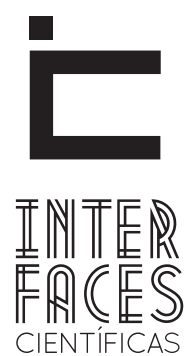

EDUCAÇÃO

ISSN IMPRESSO 2316-333X

ISSN ELETRÔNICO 2316-3828

\title{
A BIBLIOTECA INFANTIL AGLAÉ FONTES DE ALENCAR E SUA IMPORTÂNCIA NO PROCESSO DE LETRAMENTO E NA FORMAÇ̃̃O DO LEITOR
}

Claudia Laís Costa da silva Campos ${ }^{1}$

\section{RESUMO}

Este artigo tem por objetivo analisar a importância da Biblioteca Infantil Aglaé Fontes de Alencar no processo de letramento e na formação do leitor, para isso apresentaremos a relevância da biblioteca infantil, bem como a forma como ela é organizada, as atividades que oferece, e a sua influência no processo de leitura e escrita de um leitor letrado. Apresentaremos os dados coletados sobre a Biblioteca, enfatizando as atividades que desenvolve e o acervo que oferece, o público que atende, como também faremos uma bre- ve apresentação sobre a sua história. A metodologia utilizada foi uma pesquisa de campo, com o intuito de colher os dados necessários para a realização desse artigo. Logo após foi realizada uma pesquisa bibliográfica, presente através do embasamento teórico utilizado nesse trabalho.

\section{PALAVRAS-CHAVE}

Biblioteca Infantil. Leitura. Formação do leitor. 


\section{ABSTRACT}

This article aims to analyze the importance of the Children's Library Aglaé Sources Alencar in the literacy process and the training of the player, so it will present the importance of children's library, as well as how it is organized, the activities it offers, and its influence on the reading and writing of a literate reader process. We will present the data collected on the library, emphasizing the activities performed and the collection that offers the public it serves, but also we

\section{RESUMEN}

Este artículo tiene como objetivo analizar la importancia de Infantil Biblioteca Aglaé Fuentes Alencar en el proceso de alfabetización y la formación del jugador, por lo que presentará la importancia de la biblioteca infantil, así como la forma en que está organizada, las actividades que ofrece, y su influencia en la lectura y la escritura de un proceso lector sabe leer y escribir. Vamos a presentar los datos recogidos en la biblioteca, haciendo hincapié en las actividades realizadas y la colección que ofrece el público al que sirve, pero will make a brief presentation about their history. The methodology used was a field survey in order to collect data necessary to conduct this article. Soon after a literature search was conducted; through this theoretical framework used in this work.

\section{KEYWORDS}

Children's Library. Reading. Formation of the reader.

también vamos a hacer una breve presentación sobre su historia. La metodología utilizada fue un estudio de campo con el fin de recopilar los datos necesarios para llevar a cabo este artículo. Poco después se realizó una búsqueda en la literatura; a través de este marco teórico utilizado en este trabajo

\section{PALABRAS CLAVE}

Biblioteca Infantil. Lectura. Formación del lector. 


\section{INTRODUÇ̄̃̃O}

Pensar a Educação Infantil é na essência, respeitar e considerar o valor dessa fase de desenvolvimento do homem, na formação de cidadãos plenos, sabedores de seus valores e potenciais, conscientes de que podem contribuir para uma sociedade ajustada e equilibrada, no sentido da observância da ética e da aceitação do outro.

É fundamental desenvolver, desde cedo, nas crianças o hábito de ler, para que quando atinja a fase adulta, ela possa se tornar um leitor crítico acerca dos livros e de todos os tipos de leituras que entram em contato, a criança passa a lidar cada vez mais com conceitos (desenvolvimento cognitivo) e à medida que cresce, pode expressá-los cada vez melhor através da linguagem, da comunicação, trabalhando na construção e reconto de histórias, lendas produção de texto e através dos jogos e das brincadeiras de roda, na pré-escola, ela irá desenvolver a capacidade de repartir, de respeitar e de lidar com as frustrações, pois é nessa fase que a criança começa a socializar-se. 0 aspecto social compreende o elemento marcante no ato lúdico vivenciado pela criança, é sem dúvida, um dos componentes de seu desenvolvimento.

Sabe-se que, para formar bons leitores é preciso que a escola, juntamente com a família promova a aproximação da criança com o mundo imaginário e mágico que os livros infantis apresentam para ela. Assim, pode-se destacar a suma importância da biblioteca infantil que, nesse contexto, torna-se indispensável nessa tarefa de formar bons leitores.

A biblioteca infantil tem o compromisso de estimular a prática de leitura nas crianças, desenvolvendo suas aptidões e seu senso de responsabilidade, tornando-a um membro proveitoso e vantajoso para a sociedade. É preciso assim dirigir-se por princípios em que o foco seja a criança enquanto um ser ativo, construindo conhecimentos sobre o mundo e sobre si mesma.
No entender de Panet (1988), as bibliotecas infantis junto com os educadores devem criar oportunidade para discussões, troca de ideias, ou seja, proporcionando ocasiões para que a criança além de desfrutar de recursos que não encontra em casa possa ler, falar, ouvir, desenvolver seu vocabulário e espírito crítico. Por isso a biblioteca infantil deve ser um espaço planejado e montado especialmente para tornar esse primeiro contato com os livros o mais agradável e natural possível a fim de atingir dessa forma um de seus objetivos maiores que é fazer da criança um usuário constante e atuante em bibliotecas.

Sabe-se que a biblioteca é fundamental para o processo de ensino e aprendizagem dos alunos desde as séries iniciais. 0 acesso e uso das informações através destas proporcionam ao aluno condições de desempenho na sua formação acadêmica. Mas para obter acesso fácil a essas informações, a biblioteca precisa ter uma política de organização. E é nesse sentido que este trabalho mostra a importância da biblioteca infantil Aglaé Fontes de Alencar

Para Meireles (1984), “A biblioteca infantil corresponde a uma necessidade da nossa época, frente às profundas transformações vividas pela família e pela sociedade como um todo". Se ao nascer, a criança já é "leitora" do que a rodeia, sua frequência à mesma poderia anteceder à matrícula escolar, iniciando assim um processo saudável com os livros. Dentro dessa concepção, SANDRONI E MACHADO (1998. P. 35), comentam:

\begin{abstract}
As crianças deveriam frequentar a biblioteca desde cedo, iniciando um contato agradável com os livros ilustrados mesmo antes da matrícula escolar. Poderiam se portar na biblioteca como quisessem, ficar sentadas ou deitadas, isto é, na posição que preferissem: importaria apenas o hábito que começa, o manuseio do livro que inicia.
\end{abstract}

A biblioteca infantil é um espaço lúdico por excelência, pois é o lugar do brincar com os livros e com as letras, do faz de conta, do contar e do ouvir histórias. 
É o local onde se pode dançar desenhar e ouvir músicas, ela deve ser um convite a brincadeiras, viajar no mundo da imaginação, como relata Fragoso (2003). A autora menciona que a arte se faz presente nos momentos das brincadeiras e ressalta:

Isso é a biblioteca e seus deslumbramentos! Personagens e gente, sem nenhuma diferença, misturando o concreto e o abstrato, a rosa perfumada ao contorno do lápis. Plena de rebuliço e vozes, sem avisos nem proibições, essa biblioteca também é sem paredes.( FRAGOSO, 2003, P. 47)

Na Biblioteca Infantil as crianças terão oportunidades de uma melhor aprendizagem, de uma orientação de vida mais adequada, terão um local propício para atividades em que irão desenvolver suas habilidades, seu raciocínio, terão um senso critico mais aprimorado. A escola deve propor aos alunos atividades que os levem a desenvolver as habilidades de debater, deduzir, analisar, interpretar, concluir, conceituar, refletir, criticar, sintetizar/resumir, reproduzir, solucionar problemas, revisar e pesquisar (Antunes, 2002). Mas, para que isto seja possível, é necessário que os alunos tomem distância do aprendizado centrado na oralidade do professor e do uso quase que exclusivo do livro didático, aproximando-se cada vez mais da biblioteca - onde terão oportunidade de estudar, de conhecer e de refletir sobre vários assuntos, em diferentes abordagens e formatos.

Baseando-se nessas colocações foi que surgiu o nosso interesse em pesquisar o papel da Biblioteca Infantil Aglaé Fontes de Alencar na formação de leitores, no processo de letramento, já que se trata de uma biblioteca pública que abre espaços para a pesquisa e promove a interação entre a criança e o mundo das letras. Assim, fizemos uma visita nessa Instituição a fim de colher informações necessária para concretização desse trabalho.

Acreditamos que as crianças devem se tornar usuárias assíduas da biblioteca, aprendendo com isso a desenvolver e buscar através da informação a sua capaci- dade perspectiva de conhecer e entender o mundo em sua volta, tornando-se assim mais autônoma e desenvolvendo o seu espírito crítico mediante a leitura e as inúmeras informações adquiridas através da leitura. Dessa forma, tomando como base a importância da biblioteca infantil para a formação do leitor, discutiremos o papel da mesma no processo de ensino-aprendizagem.

Nesse sentido, viabiliza a produção do conhecimento a partir do crescimento do seu repertório cultural tendo acesso a outras visões de mundo que possibilitem estabelecer novas relações com o mundo que o cerca. É importante estimular a leitura na criança como uma experiência valiosa e prazerosa. Isso será uma grande fonte de satisfação tanto para as crianças quanto para os adultos que as acompanharem nesta aventura. A Biblioteca infantil tem como objetivo primordial familiarizar as crianças com os diversos materiais que poderão enriquecer suas horas de lazer, despertando-as para os livros e para leitura, desenvolvendo sua capacidade de expressar-se.

\section{A BIBLIOTECA INFANTILE A FORMAÇ̃̃O DO LEITOR}

A biblioteca infantil tem grande importância no desenvolvimento do hábito de leitura pela criança, e até mesmo para as crianças que ainda não estão em fase de alfabetização ela pode exercer uma grande influência para o desenvolvimento de suas competências e habilidades necessárias para a visão de sujeito crítico que ele poderá se tornar. Portanto é fundamental para o processo de ensino-aprendizagem para os alunos desde as series iniciais.

Parafraseando Silveira Bueno (1996) biblioteca é uma das forças educativas mais poderosas de que dispõem estudantes, professores e pesquisadores. 0 aluno deve investigar, e a biblioteca é o centro de investigação tanto como é um laboratório. 0 desejo de descobrir o que há nos livros, geralmente, existe nas crianças. A escola deve desenvolvê-lo, utilizando os espaços da biblioteca. 
Conforme Paulo Freire (2003, p. 11):

(...) o ato de ler não se esgota da decodificação pura da palavra escrita ou da linguagem escrita, mas que se antecipa e se alonga na inteligência do mundo. A leitura do mundo precede a leitura da palavra (...) linguagem e realidade se prendem dinamicamente.

A biblioteca infantil é uma instituição que abriga um leque de atividades desenvolvidas como oficinas de artes, contos de histórias, exposições e histórias em vídeo, não só para crianças e adolescentes, mas para a sociedade em que ela está inserida, com o intuito de fazer com que estes usuários criem um habito pela leitura, sendo assim, as crianças desenvolver inúmeras aptidões, despertando-se para o mundo imaginário, e fantasias que os contos infantis lhes apresentam.

Ribeiro (1994, p. 61) afirma que:

A biblioteca possibilita acesso à literatura e as informações para dar respostas e suscitar perguntas aos educandos, configurando uma instituição cuja tarefa centra-se na formação não só do educando como também de apoio informacional ao pessoal docente. Para atender essas premissas a biblioteca precisa ser entendida como um 'espaço democrático' onde interajam alunos, professores e informação. Esse espaço democrático pode estar circunscrito a duas funções: a função educativa e a formação cultural do indivíduo.

Exige-se da escola, principalmente, o redimensionamento de todo o trabalho educativo que engloba: ousadia, seleção de materiais variados, espaço para socialização, respeito a opiniões divergentes, enfim novas propostas de trabalhos pedagógicos com leituras críticas e variadas.

A biblioteca infantil é um espaço lúdico por excelência, pois é o lugar do brincar com os livros e com as letras, do faz de conta, do contar e do ouvir histórias. A literatura evidencia a presença do livro quando aborda as diversas possibilidades que ela pode oferecer, como por exemplo, o canto da leitura. Nessa conjuntura, o livro assume o papel de brinquedo:
Com tapetes e almofadas para acolher a criança que quer ler um livro deitada no chão ou, simplesmente, aninhar-se em busca de aconchego. Aqui os livros são usados como brinquedos e não com a seriedade com que seriam usados em uma biblioteca infantil. Esta é uma maneira de fazer com que as crianças tomem contato com os livros, de figuras ou de histórias, de forma bem prazerosa e descontraída. Afinal, a primeira forma de leitura é a leitura de figuras; é desde cedo que se cultiva o hábito de leitura (CUNHA, 1994: 17).

Nesse contexto, o contato com o livro possibilita o desenvolvimento da linguagem cultural e cognitivo nas crianças, pois estabelece novos padrões de raciocínio abrindo espaços através dos quais as mesmas possam se expressar exercitando a criatividade. 0 livro infantil informa/ forma sem perder a ludicidade, mas é difícil para o educador aplicar todo este potencial. Neste sentido, a biblioteca infantil vem ao encontro das atividades pedagógicas para dar suporte informacional e colaborar na formação do leitor. Para tanto, é necessário que o espaço dela transcenda as suas paredes e neste cenário é imperativa a busca por uma biblioteca de concepção inovadora inserida na prática pedagógica, contribuindo para o processo de ensino e aprendizagem.

A biblioteca infantil é como uma manifestação de sentimentos e palavras, que conduz a criança ao desenvolvimento do seu intelecto, da personalidade, satisfazendo suas necessidades e aumentando sua capacidade crítica. Esta literatura, como já foi expressa, tem o poder de estimular e/ou suscitar o imaginário, de responder as dúvidas do indivíduo em relação a tantas perguntas, de encontrar novas idéias para solucionar questões e instigar a curiosidade do leitor. Nesse processo, ouvir histórias tem uma importância que vai além do prazer. É através de um conto e/ou de uma história, que a criança pode conhecer coisas novas, para que efetivamente sejam iniciados a construção da linguagem, da oralidade, idéias, valores e sentimentos, os quais ajudarão na sua formação pessoal.

Considerando que o gosto pela leitura se constrói através de um longo processo e que é fundamental 
para o desenvolvimento de potencialidades, há a necessidade de se propor atividades diversas e diferenciadas para a formação do leitor crítico. De acordo com Zilberman (2003, p.30): “... o uso do trabalho na escola nasce, pois, de um lado, da relação que se estabelece com seu leitor, convertendo-o num ser crítico perante sua circunstância...”.

Muitos estudos e pesquisas têm evidenciado a importância das atividades literárias diferenciadas no contexto educacional para o bom desempenho da criança. A utilização da literatura como recurso pedagógico pode ser enriquecida e potencializada pela qualidade das intervenções do educador.

Assim, o educador preocupado com a formação do gosto pela leitura deve reservar espaços em que proponha atividades novas, sem o compromisso de impor leituras e avaliar o educando. Trata-se de operacionalizar espaços na escola e na sala de aula onde a leitura por fruição-prazer possa ser vivenciada pelas crianças e jovens.

As várias atividades propostas podem ajudar no contexto educacional, se bem utilizadas a partir de um conto: o pintar; o desenhar no contexto da história; discutir sobre as partes da história que as crianças mais gostaram; trocar experiências a partir da história contada; adivinhar o que vai acontecer e/ou imaginar finais e situações diferentes; elaborar textos; encenar uma peça teatral; utilizar papéis diversos; confeccionar novos materiais; trabalhar em grupo podem contribuir para a formação de um ser criativo, crítico, imaginativo, companheiro e provavelmente leitor.

Nesse contexto, o professor deve proporcionar várias atividades inovadoras, procurando conhecer os gostos de seus alunos e a partir daí escolher um trabalho ou uma história que vá ao encontro das necessidades da criança, adaptando o seu vocabulário, despertando esse educando para o gosto, deixando-o se expressar. Acredita-se assim que a proposta de atividades variadas é de grande valor para o processo de construção da autonomia e desenvolvimento da criança em formação.

\section{LETRAMENTO E A UTILIZAÇÃO DO ESPAÇO DA BIBLIOTECA NO PROCESSO DE CONSTRUÇÃO DA LEITURA}

Para CAGLIARI (1998) a escrita foi inventada a partir da leitura, pois o homem começou a desenhar as paredes com figuras de modo, a representar as cenas do seu cotidiano como animais, pessoas, objetos. Então, este começou a explicar para as pessoas o que vinha a ser as suas representações surgindo assim, a linguagem oral originando a leitura.

Quando a criança é inserida no contexto escolar, ela já traz um conhecimento de leitura, envolvido nas suas práticas do cotidiano, cabe a escola desenvolver o processo de letramento para conseguir um sucesso no processo de leitura vinculado à escrita.

Cabe ao professor oferecer aos seus alunos subsídios de forma a garantir estímulos para a leitura, desenvolvendo o processo de letramento, onde a escrita e a oralidade tenham sentido e façam parte da vida do aluno. Segundo Magda Soares o processo de alfabetização sempre visto numa forma restrita, passa a ser analisado de forma mais ampla no letramento.

\footnotetext{
O sentido ampliado da alfabetização, o letramento, de acordo com Magda, designa práticas de leitura e escrita. A entrada da pessoa no mundo da escrita se dá pela aprendizagem de toda a complexa tecnologia envolvida no aprendizado do ato de ler e escrever. Além disso, o aluno precisa saber fazer uso e envolver-se nas atividades de leitura e escrita. Ou seja, para entrar nesse universo do letramento, ele precisa apropriar-se do hábito de buscar um jornal para ler, de frequentar revistarias, livrarias, e com esse convívio efetivo com a leitura, apropriar-se do sistema de escrita. (SOARES 2012.p.45)
}

A autora defende que para adaptar-se de forma adequada ao ato de ler e escrever, é preciso compreender, inserir-se, avaliar apreciar a escrita e a leitura. Pois o indivíduos consegui ser alfabetizado porém não 
desenvolve competências para pôr em prática tudo que foi ensinado. Nessa perspectiva é que salientamos a importância da biblioteca nesse processo de aprendizagem da leitura e da construção da escrita, esta promoverá um enriquecimento ao vocabulário escolar da criança em pleno seu processo de alfabetização, pois o letramento consiste em adaptar as vivências adquiridas no ambiente extracurricular. Para Soares o letramento atualmente

É fundamental conhecer o funcionamento do sistema de escrita, porém devemos considerar as práticas sociais letradas. Assim, enquanto a alfabetização se ocupa da aquisição da escrita, o letramento se preocupa com a função social do ler e do escrever.

E a expressão letramento apareceu ao lado da alfabetização por se considerar o domínio mecânico da leitura e da escrita insuficiente na sociedade atual. Tornou-se objetivo da escola introduzir os alunos nas práticas sociais de leitura e escrita, pois deixou de ser satisfatório em sua formação o desenvolvimento específico da habilidade de codificar e decodificar a escrita.

É necessário mais do que apresentar para os alunos as letras e sua relação com os sons, às palavras e as frases. É preciso trabalhar com textos reais estimulando a leitura e a escrita dos diversos gêneros textuais para que aprendam a diferenciá-los e a perceber a funcionalidade de cada um dos textos (SOARES, 2012 p.125).

Soares (2012) analisa a presença do letramento numa forma mais ampla, que a evolução da leitura e da escrita é uma tendência natural, que por meio de atividades lúdicas poderá ser desenvolvida, com o apoio ao desenvolvimento da linguagem falada e ao processo de aquisição da linguagem escrita.

O letramento está muito presente na Educação Infantil, no momento em que as crianças estão imersas ao "mundo" visual, as propagandas, nos vídeos que costumam assistir, dessa forma percebemos o interesse desde cedo pelas palavrinhas e pelas imagens que existem nos livros, as crianças ficam motivadas pelo significado das mensagens transmitidas nas literaturas.

\section{A PRÁTICA SOCIAL DA LITERATURA INFANTIL}

Pode-se perceber que a literatura é indispensável na escola como meio necessário para que a mesma compreenda o que acontece ao seu redor e para que seja capaz de interpretar diversas situações e escolher os caminhos com os quais se identifica.

Entende-se que a leitura é um dos caminhos de inserção no mundo e da satisfação de necessidades do ser humano. No entanto, muitos professores desconhecem a importância da leitura e da literatura mais especificamente por ignorar seu valor e/ou por falta de informação.

A prática educativa com a literatura nas séries iniciais do ensino fundamental quase sempre se resume em textos repetitivos, seguidos por cópias e exercícios dirigidos e mecânicos, onde o espaço para reflexão e compreensão sobre si e sobre o mundo raramente encontra lugar.

Não podemos nos referir à leitura como um ato mecânico sem a preocupação de buscar significados. Desse modo, é necessário que dentro do ambiente escolar o professor faça a mediação entre o trabalho e o aluno, para que assim sejam criadas situações onde o aluno seja capaz de realizar sua própria leitura, concordando ou discordando e ainda fazendo uma leitura crítica do que the foi apresentado.

Daí a importância em se propiciar a leitura e a literatura de modo a permitir ao aluno criar e recriar o universo de possibilidades que o texto literário oferece. Pode-se dizer que a escola tem a oportunidade de estimular o gosto pela leitura se consegue promover de maneira lúdica o encontro da criança com o trabalho.

A esse respeito Zilberman descreve que:

a sala de aula é um espaço privilegiado para o desenvolvimento do gosto pela leitura, assim como um campo importante para o intercâmbio da cultura literária, não podendo ser ignorada, muito menos desmentida sua utilidade. Por isso, o educador deve adotar uma postura criativa que estimule o desenvolvimento integral da criança. (Zilberman 2003, p. 16) 
Sabe-se que a literatura é um processo de continuo prazer, que ajuda na formação de um ser pensante, autônomo, sensível e crítico que, ao entrar nesse processo prazeroso, se delicia com historias e textos diversos, contribuindo assim para a construção do conhecimento e suscitando o imaginário.

É perceptível que quando bem utilizado no ambiente escolar, o trabalho de literatura pode contribuir ainda para o desenvolvimento pessoal, intelectual, conduzindo a criança ao mundo da escrita. Dessa forma, a biblioteca infantil tem sua importância na escola e torna-se indispensável por conter todos os aspectos aqui levantados, sendo de grande valor por proporcionar o desenvolvimento e a aprendizagem da criança em sua amplitude.

\section{UM POUCO DA HISTÓRIA DA BIBLIOTECA INFANTIL AGLAÉ FONTES DE ALENCAR}

Em novembro de 1934, Sergipe, especialmente Lagarto, ganhou um presente que muito contribuiria para a pesquisa, a arte e a educação. Nascia Aglaé Fontes de Alencar. Começou a cantar e recitar poesia na igreja com incentivo de sua mãe. Sua família morou em várias cidades do interior sergipano, permitindo que a jovem descobrisse o folclore e suas manifestações. Formada em Filosofia pela Universidade Federal de Sergipe, especializou-se em Educação Pré-Escolar e na Universidade Federal da Bahia, formou-se em Educação Musical. Fundou a Escolinha de Música, para crianças. Foi professora de psicologia da aprendizagem na Universidade Federal de Sergipe e Diretora do Centro de Criatividade onde desenvolveu uma metodologia de ensino voltada a diversas expressões das artes. Foi Secretária de Cultura de Educação do Estado. Atualmente, aposentada, trabalha em consultoria para artes e ministra cursos a professores em algumas cidades do Estado e em Portugal. Como escritora, escreveu várias peças de teatro que foram montadas pelos grupos Expressionistas e mamulengo Cheiroso.
A biblioteca Infantil Aglaé Fontes de Alencar foi fundada como anexo da Biblioteca Epifânio Dórea em 29 de outubro de 1974, sua primeira diretora foi a professora Aglaé Fontes de Alencar somente no ano de 1985 foi desmembrada da Biblioteca Pública Epifânio Dórea.

De 1989 a 2002 a mesma passou por uma série de transformações. Foi gerida por várias diretoras. Tem como diretora a bibliotecária Cláudia Stocker (ex-aluna da UNIT do curso de biblioteconomia) trabalha a um ano nesta referida biblioteca e conta com uma experiência de sete anos como bibliotecária em escolas pública. Desde que assumiu a direção a biblioteca vem passando por várias reformas como, por exemplo, aumento no número de freqüência; aumentou o horário de funcionamento (funciona da 8:00 às 17:00h), tornou o ambiente mais atrativo com aspectos infantis, o número de empréstimos aumentaram tanto a nível de empréstimos escolares como a comunidade em que está inserida. 0 acervo foi todo informatizado.

Para Cláudia Stocker (2012) biblioteca infantil “é o espaço lúdico onde a criança trabalha a leitura através de diversas atividades e que desperte o lado crítico e cultural da criança". A biblioteca Infantil Aglaé Fontes de Alencar tem como objetivo disseminar a informação, incentivar a leitura ao público infantil através de atividades de contação de histórias, oficinas, teatro de fantoches, exposições e outras atividades culturais.

A citada biblioteca conta com uma gibiteca, salas de leituras e oficinas. Tem como público alunos de escolas da rede pública e privada além das crianças da comunidade. Dentro as suas programações estão às oficinas de desenho e pinturas, contações de histórias, exposições e depende muito das datas comemorativas.

A biblioteca infantil Aglaé Fontes de Alencar é o reflexo do seu ambiente externo e interno. Com relação ao ambiente externo, a biblioteca está localizada 
em um local que favorece a sua visualização, longe de ruídos oriundos de ruas e avenidas, corredores e quadras de esportes, totalmente confortável ao público que freqüenta. Um lugar propício às atividades de leitura e de pesquisa para os usuários e para os profissionais que nela atuam.

A higienização da biblioteca é outro ponto a ser destacado, há uma boa higienização que é um fator favorável importante para a saúde e o bem estar de seus frequentadores e para a preservação e conservação do acervo.

\section{ACERVO}

Dentre as várias atividades desenvolvidas pela biblioteca Infantil Aglaé Fontes de Alencar, a formação da coleção é preocupação constante, pois é a partir desta que se desenvolvem os produtos e serviços da biblioteca infantil.

A biblioteca conta com um acervo de $5.285 \mathrm{li}$ vros para a pesquisa escolar como enciclopédia e coleções, literatura infantil com diversos títulos de autores, a exemplo de Monteiro Lobato, Ruth Rocha, Ziraldo e outros autores, além de clássicos de Walt Disney e como os Irmãos Grimm, contos e literatura infanto-juvenil, além de uma riquíssima Gibiteca, composta por 1,135 histórias em quadrinhos décadas de 60, 70, 80 até os dias atuais, e várias revistas infantis.

O valor do acervo da biblioteca dá-se pelo fato de facilitar aos usuários o acesso ao saber socialmente elaborado. A oralidade não é o principal meio de transmissão e circulação desse saber. É por meio da escrita que ele pode ser recuperado, estudado e pesquisada para as propostas de ensino-aprendizagem. Portanto, o investimento na coleção da biblioteca infantil é aspecto fundamental, uma vez que esta representa uma possibilidade de inserção social de seus usuários.
Para Sales (2002, p. 10), o acesso à informação variada e atualizada é condição para o exercício da cidadania, pois esta "se manifesta e se constrói a partir da conscientização e da participação social e política dos homens na sociedade, o que pressupõe também o acesso a informações variadas e atualizadas."

0 acervo da biblioteca infantil serve para cativar e estimular, nos usuários, o interesse pela sua utilização. Por essa razão, é necessária a sua diversificação, respeitando a faixa etária e o interesse do usuário, tanto em relação ao suporte físico quanto aos diferentes temas e abordagens.

Segundo Figueiredo (1999, p. 57)

Apesar de toda a ênfase moderna na prestação de serviço aos usuários, uma biblioteca ainda é, essencialmente, uma coleção de livros e outros tipos de materiais. Nenhuma prestação de serviço pode substituir uma coleção pobre, e sendo a coleção a base para qualquer serviço, este deixará a desejar, se não tiver suporte numa coleção criteriosamente desenvolvida, de acordo com os interesses/necessidades de informação da comunidade de usuários.

0 acesso e uso das informações através das bibliotecas infantis proporcionam ao aluno condições de desempenho na sua formação. Mas para obter acesso fácil a essas informações, a biblioteca precisa ter uma política de organização.

\section{CONSIDERAÇÕES FINAIS}

Para a criança em seus primeiros estágios, a palavra não é um símbolo do objeto, porém a parte do todo mesmo. 0 que vai existir inicialmente é uma apropriação externa, do signo, e só mais tarde o caráter simbólico irá ser desenvolvido. Uma criança emprega a palavra para nomear, e o desenvolvimento desta vai depender das interações realizadas com os adultos, e este desenvolvimento que ela produz resultará na aprendizagem. 
Desta forma é que se concluiu com esta pesquisa que a linguagem está relacionada à aprendizagem, e juntas ganham força na interação, a aprendizagem se torna um processo de interiorização, que será construído e desenvolvido a partir do contato cognitivo, das experiências decorrentes das relações sociais.

Nessa percepção é possível enfatizar que o ambiente interfere nas atividades dos indivíduos, na interiorização, tendo as transformações do comportamento proporcionadas pela internalização, assim o aprendizado ocorre de acordo com o contexto histórico cultural.

O meio, que é considerado como tudo que envolve a cultura, a sociedade, as práticas e as interações é fator fundamental no desenvolvimento humano, afirma Vigotski (2003), o contexto cultural do sujeito vai sendo movido pelas suas interações sociais, assim como suas relações intra e interpessoais e de troca com o meio, a partir do processo denominado mediação, dessa forma a interação da criança com o espaço da biblioteca vai influenciá-la na construção da sua linguagem, no desenvolvimento intelectual.

Para Vigotski, as características individuais, as atitudes dos indivíduos, estão impregnadas de trocas com o coletivo, à linguagem torna-se um elemento de comunicação e expressão essencial no processo comunicativo para efetivação da construção do conhecimento. Sabe-se que é inerente ao homem a necessidade de interagir e manter contato com o outro criando uma relação de aproximação e, por conseguinte, com o mundo em que vive, além disso, pode-se notar também que a comunicação se torna elemento fundamental para concretização dessa ação de interação.

A linguagem desenvolvida através de um processo social tanto na escola como num ambiente externo de aprendizagem vai estabelecer um papel fundamental na determinação de como o sujeito vai desenvolver o seu pensamento, uma vez que essas formas de pensamento serão transmitidas as crianças através das palavras, que serão por estas internalizadas e posteriormente expressas. 0 pensamento e suas formas de atividades não são totalmente naturais, mas um sistema híbrido em que sua capacidade biológica são possibilitadas pelas construções culturais dos grupos.

Para Paulo Freire (1982) é necessário considerar a realidade social, pois ela esta pautada na trama das relações e nas correlações das forças que compõem a totalidade social, visto que nenhum fato ou fenômeno se justifica por si mesmo, isolado do contexto social, onde ele será gerado e desenvolvido. Para o autor a relação sujeito-sujeito e sujeito-mundo são indissociáveis.

Nessa perspectiva entre a construção do conhecimento e desenvolvimento da linguagem é que foi importante a construção dessa pesquisa para entender o quanto o uso da biblioteca na infância como espaço de aprendizagem poderá proporcionar desempenho na construção do pensamento crítico e intelectual.

\section{REFERÊNCIAS}

ANTUNES, C. Como transformar informações em conhecimento. 2. ed. Rio de janeiro: Vozes, 2002. 37 p. (Na Sala de Aula, 2).

ANTUNES, C. Onde estão as bibliotecas escolares? Cadernos do CED, Florianópolis, v. 4, n. 10, p. 58-66, abr./jun. 1987.

BARBOSA, Laura Caroline Aoyama; PASTANA, Maria Teresa Maranha; SACHETTI, Vana Fátima Preza. Biblioteca escolar: uma questão a ser resolvida: perfil das bibliotecas escolares em Rondonópolis. Projeto de pesquisa em Biblioteconomia da UFMT. Rondonópolis, MT, 2000.

BUENO, Silveira. Dicionário da língua portuguesa. São Paulo: FTD, 1996. 
CAGLIARI, Luiz Carlos. Alfabetização e lingüística. 10. ed. São Paulo: Scipione, 2002.

Cunha, N.H.S. Brinquedoteca: um mergulho no brincar. São Paulo: MALTESE.1994.

FIGUEIREDO, N. de M. Paradigmas modernos da ciência da informação: em usuários, coleções, referência e informação. São Paulo: Polis: APB, 1999. 168 p. (Coleção Palavra-chave, 10).

FRAGOSO, G. M. Biblioteca na escola. Revista ACB: Biblioteconomia em Santa Catarina, Florianópolis, v. 7, n. 1, p. 124-131, 2002.

FREIRE, Paulo. A Importância do ato de ler: em três artigos que se completam. 44. ed. São Paulo: Cortez, 2003.

MEIRELES, Cecília. Problemas da literatura infantil. 3. ed. Rio de Janeiro: Nova Fronteira, 1984.

PANET, Carmem de Farias. Implantação e funcionamento de bibliotecas infanto-juvenis. João Pessoa: Editora Universitária, UFPB, 1988.
RIBEIRO, M. S. P. Desenvolvimento de coleção na biblioteca escolar: uma contribuição à formação crítica sócio-cultural do educando. Trans-informação, São Paulo, v.6, n.1/2/3, p. 60-73, jan./dez. 1994.

SALES, F. de. A biblioteca na construção da cidadania. 2002. 36 f. Monografia (Especialização em Direitos Humanos e Cidadania) - Centro de Ciências da Educação, Universidade do Estado de Santa Catarina, Florianópolis, 2002.

SANDRONI, Laura C.; MACHADO, Luiz Raul. A criança e o livro: guia prático de estímulo à leitura. $4^{\mathrm{a}}$ ed. São Paulo: Ática, 1998.

SOARES, Magda. Alfabetização e Letramento. Editora Contexto. 2012.

VYGOTSKI, Lev Semenovich. A construção do pensamento e da linguagem. Tradução Paulo Bezerra. São Paulo: Martins Fontes, 2001. (Psicologia e pedagogia).

ZILBERMAN, R. A literatura infantil na escola . São Paulo: Global. 2003. 